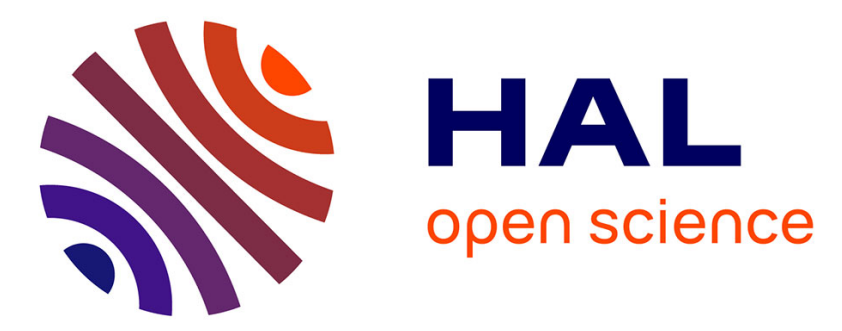

\title{
Subject Specific Finite Element Mesh Generation of the Pelvis from Biplanar X-ray Images: Application to 120 clinical cases
}

Nolwenn Fougeron, Pierre-Yves Rohan, Aurélien Macron, Christophe Travert, Hélène Pillet, Wafa Skalli

\section{To cite this version:}

Nolwenn Fougeron, Pierre-Yves Rohan, Aurélien Macron, Christophe Travert, Hélène Pillet, et al.. Subject Specific Finite Element Mesh Generation of the Pelvis from Biplanar X-ray Images: Application to 120 clinical cases. Computer Methods in Biomechanics and Biomedical Engineering, 2018, 21 (5), pp.408-412. 10.1080/10255842.2018.1469624 . hal-02180730

\section{HAL Id: hal-02180730 https://hal.science/hal-02180730}

Submitted on 11 Jul 2019

HAL is a multi-disciplinary open access archive for the deposit and dissemination of scientific research documents, whether they are published or not. The documents may come from teaching and research institutions in France or abroad, or from public or private research centers.
L'archive ouverte pluridisciplinaire HAL, est destinée au dépôt et à la diffusion de documents scientifiques de niveau recherche, publiés ou non, émanant des établissements d'enseignement et de recherche français ou étrangers, des laboratoires publics ou privés. 


\title{
Subject Specific Finite Element M esh Generation of the Pelvisfrom Biplanar X-ray Images: Application to 120 clinical cases
}

\author{
Nolwenn Fougeron ${ }^{1 *}$ Pierre-Yves Rohan ${ }^{1}$ Aurélien Macron ${ }^{12}$ Christophe Travert ${ }^{1}$ AQ2 Hélène \\ Pillet ${ }^{1}$ Wafa Skalli ${ }^{1}$
}

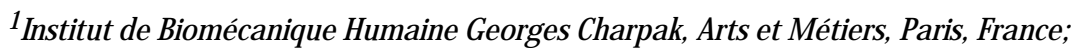

${ }^{2}$ CEA, LETI, CLINATEC, M INATEC Campus, Grenoble, France

*AQ3CONTACT Nolwenn Fougeron nolwenn.fougeron@ensam.eu

\begin{abstract}
Several Finite Element (FE) models of the pelvis have been developed to comprehensively assess the onset of pathologies and for clinical and industrial applications. However, because of the difficulties associated with the creation of subject-specific FE mesh from CT scan and M R images, most of the existing models rely on the data of one given individual. M oreover, although several fast and robust methods have been developed for automatically generating tetrahedral meshes of arbitrary geometries, hexahedral meshes are still preferred today because of their distinct advantages but their generation remains an open challenge. Recently, approaches have been proposed for fast 3D reconstruction of bones based on X-ray imaging. In this study, we adapted such an approach for the fast and automatic generation of all-hexahedral subject-specific FE models of the pelvis based on the elastic registration of a generic mesh to the subject-specific target in conjunction with element regularity and quality correction. The technique was successfully tested on a database of 120 3D reconstructions of pelvises from biplanar X-ray images. For each patient, a full hexahedral subject-specific FE mesh was generated with an accurate surface representation.
\end{abstract}

KEYWORDS Biplanar X-rays; Finite Element M odelling; Hexahedral M esh; Pelvis; Subject Specific

\section{Introduction}

Finite Element Modelling of the pelvis is becoming an ever more important tool for investigating the mechanisms responsible for the onset and the development of pathologies (Filardi et al. 2017). It also constitutes a valuable tool for the development and evaluation of medical devices (Watson et al. 2017), haptic medical training devices (Buttin et al. 2013) and have the potential of improving both prevention strategies (Linder-Ganz et al. 2008) and surgical planning (Liu et al. 2016).

FE models of the pelvis are generally built from patient-specific Computed Tomography (CT) data (Anderson et al. 2005) which, in addition to the lengthy acquisition times, requires intensive user intervention at multiple stages of the segmentation process and for the FE mesh design (Salo et al. 2015). For this reason, existing models generally rely on the data of only one individual and, except for a few attempts, the question of personalization in a framework compatible with clinical routine remains an open question.

Moreover, although several fast and robust methods have been developed for automatically generating tetrahedral meshes of arbitrary geometries ( $\mathrm{Si}$ 2015), hexahedral meshes are still preferred today because of their distinct advantages over standard displacement-based tetrahedral elements namely (i) reduced order of convergence for strains and stresses (Payen and Bathe 2011) and (ii) stability issues associated to shear locking, volumetric locking (Joldes et al. 2009). Yet the automatic generation of all-hexahedral FE meshes for complex geometries remains an open challenge and research is still ongoing Gregson et al. (2011).

Recent developments in 3D reconstruction techniques from calibrated biplanar X-ray imaging provide a promising alternative tool for patient-specific validated 3D modelling of the pelvis (Ghostine et al. 2017). Unlike CT scanner or MRI systems where the patient is in a supine position, this technique provide biplanar images of the subject in a standing position. 
The aim of this contribution is to develop a methodology for the automatic hexahedral subject specific FE mesh design of the pelvis based on 3D reconstruction from biplanar X-rays suitable for FE simulations.

\section{Materials and methods}

\subsection{Biplanar X-ray acquisition and 3D reconstruction of the pelvis}

Images and associated 3D semi-automatic reconstructions were derived from EOS biplanar radiographs (Dubousset et al. 2010) (EOS Imaging, Paris, France) of 120 subjects (57 females, 63 males) collected in previous studies (Surets et al. 2005; Chaibi et al. 2012; Quijano et al. 2013; Pillet et al. 2014; Sangeux et al. 2014; Ohl et al. 2015; Amabile et al. 2016; Bendaya et al. 2016; Zhang et al. 2016; Ghostine et al. 2017). Ages, weights and heights were comprised between 20 and 76 years old, 42 and $120 \mathrm{~kg}$ and 150 and $190 \mathrm{~cm}$. For each patient, the 3D geometry of the pelvis was reconstructed using previously described validated techniques (Ghostine et al. 2017) by experienced users. Each reconstruction takes around 20 minutes.

\subsection{Generic mesh design}

Female and male pelvises were distinguished due to their anatomical differences. The generic anatomical atlases of both pelvises used for the 3D reconstructions were used to design the respective generic FE meshes. Non-uniform rational B-spline (NURBS) surfaces were generated over the triangular surface meshes of the anatomical atlases using Geomagic Studio (Geomagic U.S. Corp., Research Triangle Park, NC, USA). Owing to the complex shape of the sacrum the surface mesh was closed at the entrance of the sacral canal. The surface patches were then used to define a virtual partitioning of the pelvic volume into cubic interior volumes in ANSYS Mechanical APDL (ANSYS Inc., Canonsburg, Pennsylvania, USA) and meshed using linear hexahedral elements.

\subsection{Kriging interpolation}

For each subject, the personalised hexahedral FE mesh was obtained by computing the geometrical deformation of the source mesh (surface nodes of the generic FE mesh) to the target mesh (nodes of the 3D surface mesh reconstruction). This deformation was performed using a dual kriging algorithm (Trochu 1993). A particular attention was paid to the following functional areas: the acetabulum, the sacral promontory and the ischial tuberosities where higher density of control points was attributed. The kriging transformation was then applied to whole hexahedral FE mesh to define the patient specific mesh of the pelvis (Figure 1).

Figure 1. Design of the patient specific mesh. (a) EOS images and the 3D semi-automatic reconstruction associated to the patient (lasts $20 \mathrm{~min}$ ). (b) Virtual Generic 3D reconstruction of the pelvic bone. (c) Generic FE mesh. (d) Result of the kriging of the FE mesh on the subject-specific $3 \mathrm{D}$ reconstruction.

(a)

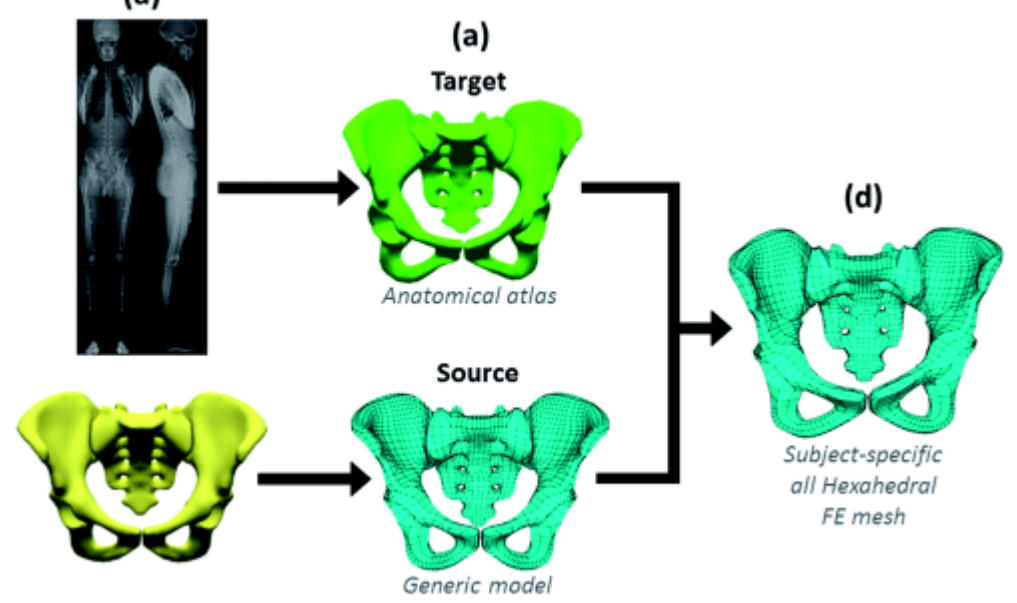

(b)

(c) 


\subsection{Mesh regularisation}

Mesh regularization of generic meshes was carried out to correct eventual excessive mesh spatial distortions. The algorithm uses an optimisation-based method to minimize the errors measured using four mesh quality metrics namely jacobian condition number, skewness, warping factor and parallel deviation. Briefly, an objective function defined as the weighted sum of the four metrics is minimised using the conjugate gradient method. The resulting mesh quality was subsequently analysed using standard ANSYS Mechanical APDL mesh quality metrics: Aspect Ratio, Parallel Deviation, Maximum Angle, Jacobian Ratio and Warping Factor.

\subsection{Point-to-surface comparison}

For verification purposes, the personalised surface FE mesh was compared to the initial 3D reconstruction surface mesh. Point (nodes of source FE mesh) to-surface (target 3D reconstruction mesh) distances were computed in 3 zones: (i) contact zones (ii) zones of high curvature and (iii) the remaining zones.

\section{Results}

\subsection{Generic FE M esh}

The generic female FE mesh and male FE mesh are composed of 3014 and 2746 linear hexahedral elements respectively. Table 1 summarizes the mesh quality metrics before and after mesh regularization.

Table 1. Quality of the generic meshes.Table Layout

\begin{tabular}{|c|c|c|c|c|c|}
\hline Models & & Male model $1 \dagger$ & Male model $2 \dagger$ & Female model $1 \dagger$ & Female model $2 \dagger$ \\
\hline \multirow[t]{2}{*}{ Aspect ratio } & Warning & 0 & 0 & 0 & 0 \\
\hline & Error & 0 & 0 & 0 & 0 \\
\hline \multirow[t]{2}{*}{ Parallel deviation } & Warning & 72 & 28 & 91 & 19 \\
\hline & Error & 0 & 0 & 0 & 0 \\
\hline \multirow[t]{2}{*}{ Maximum angle } & Warning & 240 & 0 & 265 & 0 \\
\hline & Error & 0 & 0 & 0 & 0 \\
\hline \multirow[t]{2}{*}{ Jacobian ratio } & Warning & 24 & 0 & 20 & 0 \\
\hline & Error & 3 & 0 & 2 & 0 \\
\hline \multirow[t]{2}{*}{ Warping factor } & Warning & 138 & 0 & 249 & 0 \\
\hline & Error & 1 & 0 & 0 & 0 \\
\hline
\end{tabular}

$\dagger$ Index 1 are models before regularization and index 2 are models after regularization. Warn means number of elements above the warning thresholds and Error the number of elements above the error thresholds.

\subsection{Personalised FE Mesh}

Table 2 summarises the average and maximal values of the quality metric for the 120 personalised FE meshes for both the female subject specific meshes and male subject specific meshes. Overall, the kriging interpolation does not introduce irregular or low quality elements that need to be repaired before proceeding to FE analysis.

Table 2. Resulting quality of the subject specific meshes. Table Layout

\begin{tabular}{|c|c|c|c|c|}
\hline \multirow[b]{2}{*}{ Tolerance $\dagger$} & \multicolumn{2}{|c|}{ Male subject-specific model } & \multicolumn{2}{|c|}{ Female subject-specific model } \\
\hline & Average & Maximum & Average & Maximum \\
\hline Aspect ratio & 0 & 0 & 0 & 0 \\
\hline Parallel deviation & 34 & 45 & 41 & 50 \\
\hline Maximum Angle & 6 & 45 & 3 & 41 \\
\hline \multicolumn{5}{|c|}{$\begin{array}{l}\text { † Only warning values are shown because no errors occurred after the kriging. Av means average number of elements } \\
\text { above the warning thresholds for the } 120 \text { subjects and Max means maximum number of elements above the warning } \\
\text { thresholds among the } 120 \text { subjects. }\end{array}$} \\
\hline
\end{tabular}




\begin{tabular}{|c|c|c|c|c|}
\hline \multirow[b]{2}{*}{ Tolerance $\dagger$} & \multicolumn{2}{|c|}{ Male subject-specific model } & \multicolumn{2}{|c|}{ Female subject-specific model } \\
\hline & Average & Maximum & Average & Maximum \\
\hline Jacobian ratio & 0 & 0 & 0 & 0 \\
\hline Warping factor & 23 & 52 & 34 & 65 \\
\hline
\end{tabular}

Each of the subject specific FE hexahedral meshes was automatically computed in less than $0.5 \mathrm{~s}$ (Figure 2).

Figure 2. (a) Illustration of 8 generic female pelvic FE meshes (b) Illustration of 8 subject specific female pelvic FE meshes.

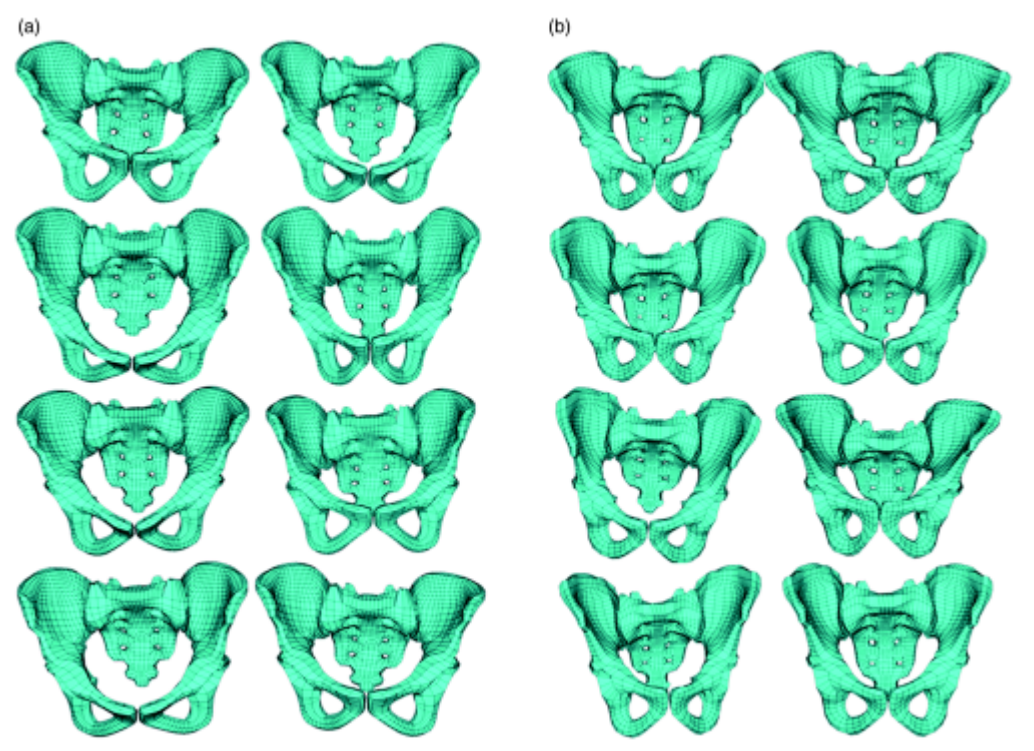

\subsection{FE surface mesh accuracy}

The average point-to-surface distances between the personalised surface FE mesh and the initial 3D reconstruction surface mesh was less than $2 \mathrm{~mm}$. The maximum (local) error was $9.6 \mathrm{~mm}$ for the females subject specific FE meshes and $11 \mathrm{~mm}$ for males subject specific FE meshes and were localized in non-functional areas (Table 3). The maximum error computed in the contact zones was inferior to $6 \mathrm{~mm}$ for the acetabulum and at the base of the sacrum and lower than $3 \mathrm{~mm}$ in the zones of high curvature such as the ischion.

Table 3. Average point-to-surface distances over the 120 personalised FE meshes. A surface was generated from the mesh of all the patient pelvis. This surface was compared to the 3D reconstruction of those pelvis in terms of point-tosurface distances. Table Layout

\begin{tabular}{|l|r|r|}
\hline Model & Male subject-specific mesh Female subject-specific mesh \\
\hline Average (mm) & 1 & 1.3 \\
\hline Standard deviation $(\mathrm{mm})$ & 1.6 & 1.8 \\
\hline Maximum $(\mathrm{mm})$ & 11 & 9.6 \\
\hline
\end{tabular}

\section{Discussion}

Generation of subject-specific FE models of the pelvis is still an open question today because they are traditionally generated from clinical CT scans - thereby exposing subjects and patients to high levels of irradiation - and generally require intensive user intervention at multiple stages of the segmentation process (Salo et al. 2015). In this contribution, 
a new methodology for the generation of subject-specific all-hexahedral FE mesh of the pelvis from biplanar X-rays imaging has been proposed. Biplanar X-ray imaging exposes individuals to much lower doses irradiation than CT-scans and can be performed in the standing position providing a promising alternative to CT-scan. Moreover, the semi-automatic 3D reconstruction process only lasts about 20 min. Combined with the fully automatic process of FE mesh generation from 3D reconstruction proposed in this contribution (which takes less than half a second) the total time to generate the personalised all-hexahedral FE mesh of the pelvis from biplanar X-rays imaging takes around 20 minutes which represents a significant decrease in both time and operator effort.

The results obtained on a database composed of 120 subjects with widely different morphologies suggest algorithm robustness. Surface errors of the subject-specific FE meshes were inferior to $1.5 \mathrm{~mm}$ on average and lower than $6 \mathrm{~mm}$ in functional areas (acetabulum, base of the sacrum and ischium). These functional areas were the focus of more specific attention due to their functional role in the biomechanical response owing to the crucial role they play in the transmission of movements and forces in both joint regions and with the surrounding soft tissues. The initial 3D reconstruction surface mesh is also known to contain inaccuracies inherent to reconstruction process. In cases where high precision is needed, digitally reconstructed radiographs could be used (Ghostine et al. 2017).

Other research teams have reported satisfactory results with atlas-based mesh morphing techniques for the fast generation of subject-specific FE mesh (Bucki et al. 2010). As compared to similar approaches, the proposed methodology allows to circumvent the segmentation of either CT scan or clinical MRI which, except for a few attempts (Bijar et al. 2016), constitutes a major bottleneck for the fast generation of FE mesh.

The method proposed in this paper is promising for clinical application because it is fast, fully automatic and allows to build subject-specific all-hexahedral FE meshes for the pelvis in a postural position. The model opens new perspectives for bringing new insights on the biomechanics of the pelvis and on the osteo-articular system in general. It has also been shown recently that locating the joint axes based on biplanar radiographs allows to have a more accurate kinematics and kinetics prediction (Sangeux et al. 2014; Sauret et al. 2016). Defining the personalised FE mesh from biplanar X-ray images would also allow to use more accurate boundary conditions for the biomechanical simulations by taking advantage of the EOS- gait analysis coupling.

\section{Financial disclosure}

The auhors would like to thank the Fondation de L'Avenir for their financial support (grant number APRM-2016-030).

\section{Conflict of interest}

The authors declare no potential conflict of interests.

\section{Author's ORCID}

Hélène Pillet

\section{References}

Amabile C, Le Huec JC, Skalli W. 2016. Invariance of head-pelvis alignment and compensatory mechanisms for asymptomatic adults older than 49 years. Eur Spine J. 27:1-9.

Anderson AE, Peters CL, Tuttle BD, Weiss JA. 2005. Subject-specific finite element model of the pelvis: development, validation and sensitivity studies. J Biomech Eng. 127(3):364-73.

Bendaya S, Anglin C, Lazennec JY, Allena R, Thoumie P, Skalli W. 2016. Good vs poor results after total hip arthroplasty: an analysis method using implant and anatomic parameters with the EOS imaging system. J Arthroplasty. 31 (9):2043-2052.

Bijar A, Rohan PY, Perrier P, Payan Y. 2016. Atlas-based automatic generation of subject-specific finite element tongue meshes. Ann Biomed Eng. 44(1):16-34.

Bucki M, Lobos C, Payan Y. 2010. A fast and robust patient specific finite element mesh registration technique: application to 60 clinical cases. Med Image Anal. 14(3):303-317. 
Buttin R, Zara F, Shariat B, Redarce T, Grangé G. 2013. Biomechanical simulation of the fetal descent without imposed theoretical trajectory. Comput Methods Programs Biomed. 111(2):389-401.

Chaibi Y, Cresson T, Aubert B, Hausselle J, Neyret P, Hauger O, de Guise JA, Skalli W. 2012. Fast 3D reconstruction of the lower limb using a parametric model and statistical inferences and clinical measurements calculation from biplanar X-rays. Comput Methods Biomech Biomed Eng. 15(5):457-466.

Dubousset J, Charpak G, Skalli W, Deguise J, Kalifa G. 2010. EOS: a new imaging system with low dose radiation in standing position for spine and bone \& joint disorders. J Musculoskeletal Res. 13(01):1-12.

Filardi V, Simona P, Cacciola G, Bertino S, Soliera L, Barbanera A, Pisani A, Milardi D, Alessia B. 2017. Finite element analysis of sagittal balance in different morphotype: forces and resulting strain in pelvis and spine. J Orthopaedics. 14 (2):268-275.

Ghostine B, Sauret C, Assi A, Bakouny Z, Khalil N, Skalli W, Ghanem I. 2017. Influence of patient axial malpositioning on the trueness and precision of pelvic parameters obtained from 3D reconstructions based on biplanar radiographs.

Eur Radiol. 27(3):1295-1302.

Gregson J, Sheffer A, Zhang E. 2011. All-hex mesh generation via volumetric polycube deformation. Eurographics Symp Geometry Process. 30(5):1407-1416.

Joldes GR, Wittek A, Miller K. 2009. Suite of finite element algorithms for accurate computation of soft tissue deformation for surgical simulation. Med Image Anal. 13(6):912-919.

Linder-Ganz E, Shabshin N, Itzchak Y, Yizhar Z, Siev-Ner I, Gefen A. 2008. Strains and stresses in sub-dermal tissues of the buttocks are greater in paraplegics than in healthy during sitting. J Biomech. 41(3):567-580.

Liu D, Hua Z, Yan X, Jin Z. 2016. Design and biomechanical study of a novel adjustable hemipelvic prosthesis. Med Eng Phys. 38(43):1416-1425.

Ohl X, Hagemeister N, Zhang C, Billuart F, Gagey O, Bureau NJ, Skalli W. 2015. 3d scapular orientation on healthy and pathologic subjects using stereoradiographs during arm elevation. J Shoulder Elbow Surg. 24(11):1827-1833.

Payen DJ, Bathe KJ. 2011. Improved stresses for the 4-node tetrahedral element. Comput Struct. 89(13):1265-1273.

Pillet H, Sangeux M, Hausselle J, El Rachkidi R, Skalli W. 2014. A reference method for the evaluation of femoral head joint center location technique based on external markers. Gait Posture. 39(1):655-658.

Quijano S, Serrurier A, Aubert B, Laporte S, Thoreux P, Skalli W. 2013. Three-dimensional reconstruction of the lower limb from biplanar calibrated radiographs. Med Eng Phys. 35(12):1703-1712.

Salo Z, Beek M, Wright D, Marisa Whyne C. 2015. Computed tomography landmark-based semi-automated mesh morphing and mapping techniques: generation of patient specific models of the human pelvis without segmentation. $J$ Biomech. 48(6):1125-1132.

Sangeux M, Pillet H, Skalli W. 2014. Which method of hip joint centre localisation should be used in gait analysis? Gait Posture. 40(1):20-25.

Sauret C, Pillet H, Skalli W, Sangeux M. 2016. On the use of knee functional calibration to determine the medio-lateral axis of the femur in gait analysis: comparison with EOS biplanar radiographs as reference. Gait Posture. 50:180-184.

Si H. 2015. Tetgen, a delaunay-based quality tetrahedral mesh generator. ACM Trans Math Softw. 41(2):11:1-11:36.

Surets S, Dorget M, Mariot JP, Barbedette B, Becquet G, Haon G. 2005. Procédé pour la fabrication d'un dispositif médical externe.

Trochu F. 1993. A contouring program based on dual Kriging interpolation. Eng Comput. 9(3):160-177.

Watson PJ, Dostanpor A, Fagan MJ, Dobson CA. 2017. The effect of boundary constraints on finite element modelling of the human pelvis. Med Eng Phys. 43:48-57.

Zhang C, Skalli W, Lagacé PY, Billuart F, Ohl X, Cresson T, Bureau NJ, Rouleau DM, Roy A, Tétreault P, et al. 2016. Investigation of 3D glenohumeral displacements from 3D reconstruction using biplane X-ray images: Accuracy and 
reproducibility of the technique and preliminary analysis in rotator cuff tear patients. J Electromyography Kinesiol. 29:12-20. 


\section{Author Queries}

Query: AQ1: Please review the table of contributors below and confirm that the first and last names are structured correctly and that the authors are listed in the correct order of contribution. This check is to ensure that your names will appear correctly online and when the article is indexed.

\begin{tabular}{|l|l|l|l|}
\hline Sequence Prefix Given name(s) & Surname Suffix \\
\hline 1 & Nolwenn & Fougeron & \\
\hline 2 & Pierre-Yves & Rohan & \\
\hline 3 & Aurélien & Macron & \\
\hline 4 & Christophe & Travert & \\
\hline 5 & Hélène & Pillet & \\
\hline 6 & Wafa & Skalli & \\
\hline
\end{tabular}

Response: Resolved

Query: AQ2: The ORCID details of the authors have been validated against ORCID registry. please check the ORCID ID details of the authors.

Response: Resolved

Query: AQ3: Please provide the missing physical address for the corresponding author.

Response: Resolved 